\begin{tabular}{|c|l|}
\hline Title & $\begin{array}{l}\text { Size distributions of organic nitrogen and carbon in remote marine aerosols: Evidence of marine biological origin based } \\
\text { on their isotopic ratios }\end{array}$ \\
\hline Author(s) & Miyazaki, Y uzo; Kawamura, Kimitaka; Sawano, Maki \\
\hline Citation & $\begin{array}{l}\text { Geophysical Research Letters, 37(6), LO6803 } \\
\text { https:/doi.org/L0.1029/2010GLO42483 }\end{array}$ \\
\hline Issue Date & 2010-03_23 \\
\hline Doc URL & http://hdl.handle.net/2115/43915 \\
\hline Rights & Copyright 2010 A merican Geophysical Union. \\
\hline Type & article \\
\hline File Information & miyazaki_GRL37.pdf \\
\hline
\end{tabular}

Instructions for use 


\title{
Size distributions of organic nitrogen and carbon in remote marine aerosols: Evidence of marine biological origin based on their isotopic ratios
}

\author{
Yuzo Miyazaki, ${ }^{1}$ Kimitaka Kawamura, ${ }^{1}$ and Maki Sawano ${ }^{1}$ \\ Received 12 January 2010; accepted 19 February 2010; published 23 March 2010.
}

[1] Size-segregated aerosol samples were collected over the western North Pacific in summer 2008 for the measurements of organic nitrogen $(\mathrm{ON})$ and organic carbon (OC). ON and OC showed bimodal size distributions. Their concentrations showed positive correlation with those of biogenic tracers, methanesulfonic acid (MSA) and azelaic acid $\left(\mathrm{C}_{9}\right)$. We found that average $\mathrm{ON}$ and $\mathrm{OC}$ concentrations were twice greater in aerosols collected in the oceanic region with higher biological productivity than in the regions with lower productivity. The average $\mathrm{ON} /$ OC ratios are higher $(0.49 \pm 0.11)$ in more biologically influenced aerosols than those $(0.35 \pm 0.10)$ in less influenced aerosols. Stable carbon isotopic analysis indicates that marine-derived carbon accounted for $\sim 46$ $72 \%$ of total carbon in more biologically influenced aerosols. These results provide evidence that organic aerosols in this region are enriched in ON that is linked to oceanic biological activity and the subsequent emissions to the atmosphere. Citation: Miyazaki, Y., K. Kawamura, and M. Sawano (2010), Size distributions of organic nitrogen and carbon in remote marine aerosols: Evidence of marine biological origin based on their isotopic ratios, Geophys. Res. Lett., 37, L06803, doi:10.1029/2010GL042483.

\section{Introduction}

[2] Marine aerosol, which comprises primary and secondary organic and inorganic components, contributes to the Earth's radiative forcing and indirectly to biogeochemical cycling of carbon and nitrogen, resulting in an impact on marine ecosystems. The possibility of an oceanic source for organic carbon (OC) in aerosol has long been recognized, due to significant $O C$ concentrations observed at oceanic sites [e.g., O'Dowd et al., 2004]. Primary emissions of biogenic organic matter via sea spray have been suggested as potential mechanisms by which phytoplankton can modulate chemical and physical properties of marine clouds. However, the formation mechanisms of secondary organic aerosol (SOA) in the marine atmosphere have not been fully clarified. Hence, global emission of oceanic OC aerosols is still highly uncertain.

[3] Organic nitrogen $(\mathrm{ON})$ compounds are subjected to chemical transformations in the troposphere, forming products that may potentially influence the chemical and physical properties of atmospheric aerosols [e.g., Zhang et

\footnotetext{
${ }^{1}$ Institute of Low Temperature Science, Hokkaido University, Sapporo, Japan.

Copyright 2010 by the American Geophysical Union. 0094-8276/10/2010GL042483
}

$a l ., 2002]$. Despite the importance of ON in marine biogeochemical cycles and its critical role in the atmosphere, the origins and chemical composition of $\mathrm{ON}$ in marine aerosols are largely unknown due to very limited studies [Duce et al., 2008]. Moreover, the relative importance of direct emissions and secondary formation of $\mathrm{ON}$ is unclear. Facchini et al. [2008] found high concentrations of dimethylamine and diethylamine in submicrometer marine aerosols in the North Atlantic, pointing an importance of alkylamines as a biological product of SOA formation.

[4] Here, we investigated size-segregated marine aerosols collected over the western North Pacific in summer to understand the sources of the aerosol ON and OC during a season of high ocean productivity. We show size distributions of $\mathrm{ON}$ and $\mathrm{OC}$, and their isotopic ratios to better discuss the relative importance of marine biological sources of organic aerosols.

\section{Experiment}

[5] Aerosol samples were collected over the North Pacific from 29 July to 19 August 2008 on board R/V Hakuho Maru (KH08-2). Figure 1 presents the cruise track, together with typical 5-day back trajectories and monthly-averaged concentrations of satellite-derived chlorophyll $a(\mathrm{Chl} a)$ for August 2008 obtained from satellite SeaWiFS data. Large regions of the western North Pacific in summer experience frequent intrusion of air from the south and southeast due to the Pacific high-pressure system, as shown by most of the back trajectories. Thus, they are ideal locations to study oceanic emissions.

[6] A total of eight sets of size-segregated aerosol samples were collected using an Andersen-type cascade impactor at a flow rate of $\sim 7.2 \mathrm{~m}^{3} \mathrm{~h}^{-1}$, located on the upper deck of the ship. Aerosol particles were collected in eight size fractions, based on the $50 \%$ equivalent aerodynamic cutoff diameters between 0.39 and $10.0 \mu \mathrm{m}$. The samples were collected on precombusted $\left(450^{\circ} \mathrm{C}, 3 \mathrm{~h}\right) 80$-mm-diameter quartz filters. Marine air was drawn for $48-72 \mathrm{~h}$ per sample without temperature or humidity controls. Possible contamination from ship exhaust was prevented by shutting off the sampling pump during beam-side airflow and/or low wind speeds $\left(<5 \mathrm{~m} \mathrm{~s}^{-1}\right)$, resulting in an effective pumping time of about $82 \%$ of the sampling period. The samples were stored in glass vials at $-20^{\circ} \mathrm{C}$ prior to analysis. We obtained aerosol size distributions for aerosol compound concentrations on each impactor stage, including the backup filters.

[7] An aliquot of filter sample was analyzed for total nitrogen (TN) and total carbon (TC) using an elemental analyzer (EA) (Carlo Erba NA 1500). Nitrogen and stable carbon isotopic analyses were also conducted using the 
(a) HBA (30 Jul.-7 Aug.)

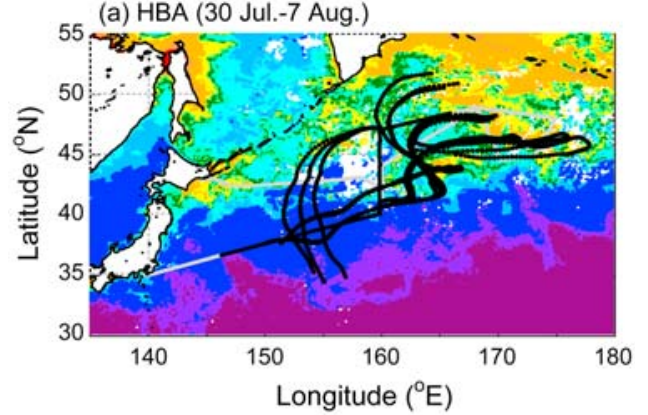

(b) LBA (9-19 Aug.)

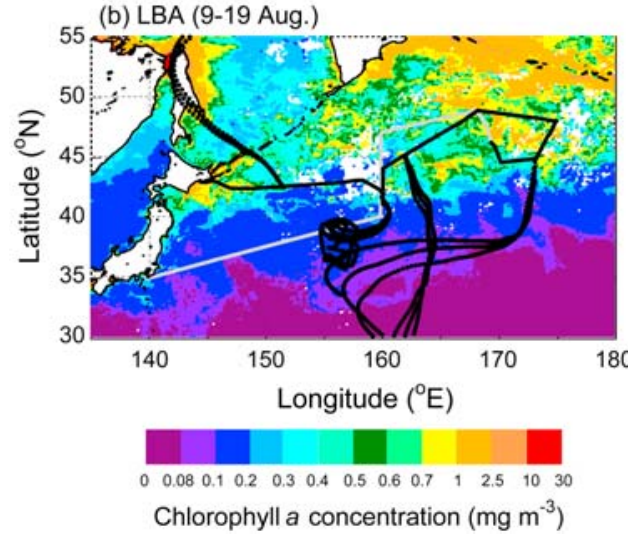

Figure 1. R/V Hakuho cruise track in the western North Pacific during (a) 30 July-7 August and (b) 9-19 August 2008, together with typical 5-day backward trajectories. Also shown are monthly-averaged concentrations of chlorophyll $a$ for August 2008 derived from SeaWiFS data, available at NASA Goddard Space Flight Center/Distributed Active Archive Centers. For definition of HBA and LBA, see text.

same EA interfaced to an isotope ratio mass spectrometer (Finnigan MAT Delta Plus) for $\delta^{15} \mathrm{~N}$ and $\delta^{13} \mathrm{C}$ measurements [Kawamura et al., 2004]. The concentrations and isotopic ratios reported here are corrected for the field blanks using the isotope mass balance equations [Turekian et al., 2003]. The blank levels of the TN and TC are $22 \%$ and $10 \%$ of the measured concentrations, respectively. The nitrogen and carbon isotope corrections were $0.9 \%$ and $0.5 \%$, respectively. Some of the samples were analyzed in duplicate and the uncertainties of TN and TC measurements were within $9 \%$, and those of the $\delta^{15} \mathrm{~N}$ and $\delta^{13} \mathrm{C}$ measurements were about $0.5 \%$.

[8] Mass concentrations of OC and elemental carbon (EC) were measured using a Sunset lab EC/OC analyzer. The equivalent $\mathrm{OC}$ concentration from field blanks accounted for $\sim 18 \%$ of the average OC concentrations of the actual samples. OC data were all corrected against field blanks. TC values measured by the EC/OC analyzer $(\mathrm{TC}=\mathrm{OC}+\mathrm{EC})$ agreed to those obtained by the EA within $7 \%$, which was equivalent to or less than uncertainties of each instrument.

[9] A filter cut of $1.54 \mathrm{~cm}^{2}$ was extracted with Milli-Q water. The total extracts $(10 \mathrm{ml})$ were then filtrated using a membrane disc filter to determine major anions and cations including diethylammonium $\left(\mathrm{DEA}^{+}\right)$by a Metrohm ion chromatograph (Model 761 compact IC). ON concentrations were calculated as the difference between $\mathrm{TN}$ and inorganic nitrogen $(\mathrm{IN})(\mathrm{ON}=\mathrm{TN}-\mathrm{IN})$. Here, $\mathrm{IN}$ is the sum of nitrate $\left(\mathrm{NO}_{3}^{-}\right)^{-}$, nitrite $\left(\mathrm{NO}_{2}^{-}\right)^{-}$, and ammonium $\left(\mathrm{NH}_{4}^{+}\right)^{- \text {nitrogen. }}$

[10] Another filter cut of $12.56 \mathrm{~cm}^{2}$ was extracted with ultra pure Milli-Q water and then analyzed for azelaic acid $\left(\mathrm{C}_{9}\right)$ and other dicarboxylic acids using a capillary gas chromatograph (GC; Hewlett-Packard GC6890N) equipped with a flame ionization detector and GC/mass spectrometry according to the method of Kawamura and Ikushima [1993].

\section{Results and Discussion}

[11] Figure 2 shows the mass size distributions of methanesulfonic acid (MSA) and azelaic acid $\left(\mathrm{C}_{9}\right)$ during the study period. MSA is produced by the atmospheric oxidation of dimethylsulfide (DMS), which is released as a gas from marine microbial processes and thus can be used as an indicator of secondary aerosols of marine biogenic origin. $\mathrm{C}_{9}$, also used as a biogenic tracer, is derived from the photooxidation of unsaturated fatty acids that are produced by marine phytoplankton and emitted to the atmosphere via marine microlayer [Kawamura and Gagosian, 1987].

[12] Three sample sets collected during the period from 30 July to 7 August showed increased concentrations of MSA and $\mathrm{C}_{9}$. The average $\mathrm{MSA} /$ non sea salt (nss) $-\mathrm{SO}_{4}^{2-}$ ratio was 0.35 . The ratio is similar to a marine biogenic MSA/ nss- $\mathrm{SO}_{4}^{2-}$ ratio $(\sim 0.33)$ at a high latitude site [e.g., Savoie et al., 2002], and is higher than those $(\sim 0.1-0.2)$ reported for marine aerosols at unpolluted mid-latitudinal sites and in the tropics [e.g., Ayers and Gras, 1991]. Moreover, $\mathrm{C}_{9}$ concentrations summed for all size ranges during this period (av. $1.30 \mathrm{ng} \mathrm{m}^{-3}$ ) is twice greater than that $\left(0.57 \mathrm{ng} \mathrm{m}^{-3}\right)$ of remote marine aerosols collected over the western North to equatorial Pacific $\left(35^{\circ} \mathrm{N}-15^{\circ} \mathrm{S}\right)$ [Kawamura and Sakaguchi, 1999]. Thus, these aerosol samples appear to have been more influenced by marine biological activity. On the other hand, MSA and $\mathrm{C}_{9}$ concentrations in the aerosol samples collected during 919 August were 3-4 times lower than those obtained during 30 July-7 August, suggesting that they were less biologically influenced than the former samples.

[13] On the basis of MSA and $\mathrm{C}_{9}$ concentrations, we classified aerosol samples into two broad categories: highly biologically influenced aerosols (HBA), comprising three sample sets taken during 30 July-7 August, and less biologically influenced aerosols (LBA), comprising four sam-
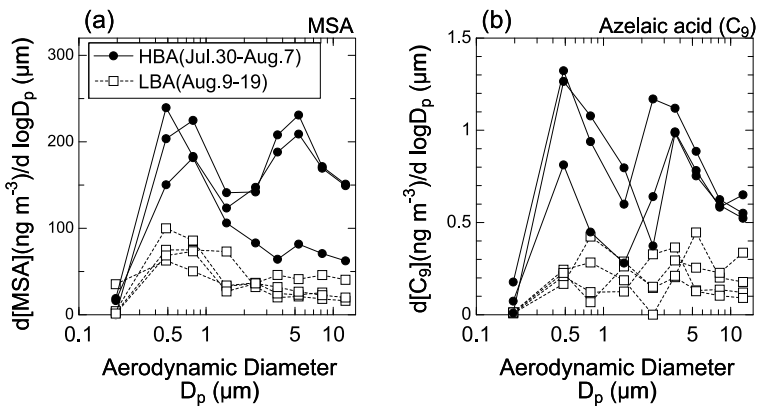

Figure 2. Size distributions of (a) methanesulfonic acid (MSA) and (b) azelaic acid $\left(\mathrm{C}_{9}\right)$ obtained during 30 July7 August (HBA) (solid circles) and during 9-19 August (LBA) (open squares). 

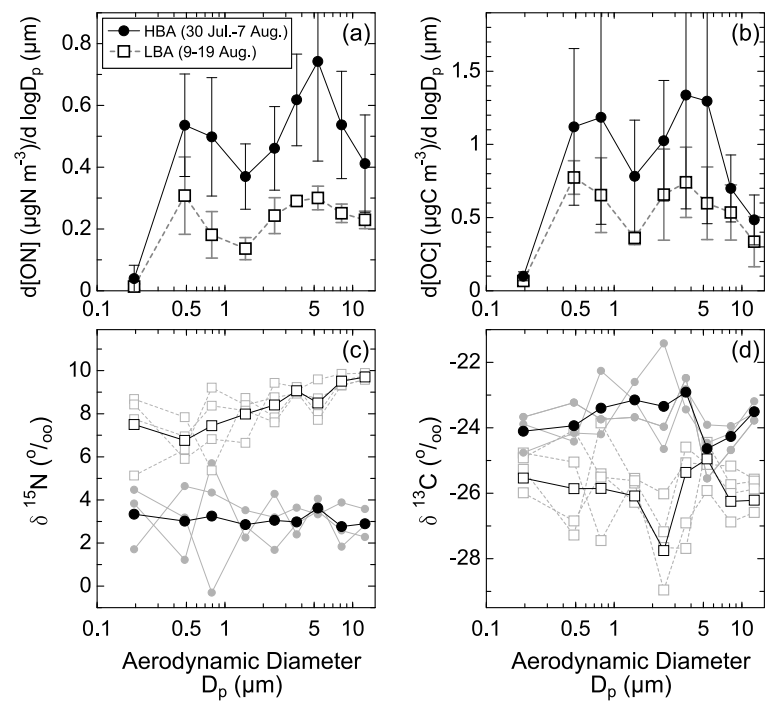

Figure 3. Size distributions of (a) $\mathrm{ON}$ and (b) $\mathrm{OC}$ together with nitrogen and stable carbon isotopic ratios of (c) TN and (d) TC, respectively, in HBA and LBA. Average $\delta^{15} \mathrm{~N}$ and $\delta^{13} \mathrm{C}$ values in HBA and LBA for each size bin are also shown.

ple sets taken during 9-19 August. In fact, the measured values of depth-integrated primary production in sea water $\left(\sim 1,039-1,480 \mathrm{mgC} \mathrm{m}^{-2} \mathrm{~d}^{-1}\right)$ during the HBA period were generally higher than those $\left(\sim 581-881 \mathrm{mgC} \mathrm{m}^{-2} \mathrm{~d}^{-1}\right)$ during the LBA period [K. Suzuki, personal communication]. Moreover, the back trajectories suggest that the sampled air masses for HBA frequently encountered high productivity regions upwind the sampling locations, whereas most of LBA originated from low productivity regions located in the south of the sampling points (Figure 1). The back trajectories, together with in situ measurements of productivity, are consistent with the increase in MSA and $\mathrm{C}_{9}$ concentrations in HBA.
[14] Figures $3 \mathrm{a}$ and $3 \mathrm{~b}$ show average size distributions of $\mathrm{ON}$ and $\mathrm{OC}$ in HBA and LBA. In all the samples, ON displayed a bimodal distribution, with the primary peak on $3.0-6.4 \mu \mathrm{m}$ range and the second peak on $0.39-0.58 \mu \mathrm{m}$ range (Figure 3a). Average ON concentrations of HBA are twice larger than those of LBA, both in submicrometer and supermicrometer ranges (Table 1). Size distribution of OC is also bimodal, with peaks at diameters of $0.39-1.0 \mu \mathrm{m}$ and $3.0-4.3 \mu \mathrm{m}$. OC concentrations of HBA are greater than those of LBA (Figure 3b). A similar ON size distribution has been observed in Hawaii [Cornell et al., 2001], although local and anthropogenic sources mainly contributed to ON. In contrast, the trajectories in this study suggest that HBA are representative of remote marine aerosols, being less affected by anthropogenic sources (Figure 1a). Insignificant contribution of anthropogenic sources to HBA is also supported by low concentrations of both $\mathrm{NO}_{3}^{-}$and $\mathrm{EC}$ in HBA (Table 1), where the EC concentrations are similar to those reported for clean marine aerosols at Mace Head [Cooke et al., 1997]. Interestingly, the average ON/OC ratio of HBA $(0.49 \pm 0.11)$ was higher than that of LBA $(0.35 \pm 0.10)$, where the difference is statistically significant at $95 \%$. In addition, both ratios are higher than typical ON/OC (0.060.11 ) reported for oceanic dissolved materials [Hansell and Carlson, 2002]. The enrichment of organic nitrogen in aerosols indicates preferential transfer of nitrogen-containing compounds from the sea surface and/or possible reactions forming nitrogen-containing organic aerosols in the marine atmosphere.

[15] HBA samples showed that ON accounted for $73 \%$ and $84 \%$ of TN in the submicrometer and supermicrometer ranges, respectively. These fractions are higher than those found in LBA samples, which showed ON/TN ratios of $67 \%$ and $80 \%$, respectively. The ON fraction was larger in the supermicrometer range of both HBA and LBA. In the submicrometer range, $\mathrm{NH}_{4}^{+}$accounted for $24 \%$ and $25 \%$ of TN in HBA and LBA, respectively. $\mathrm{NO}_{3}^{-}$was found mostly in the supermicrometer range, accounting for $6 \%$ of $\mathrm{TN}$ in HBA, which was lower than that in LBA (11\%). These

Table 1. Average Concentrations and Ratios of Different HBA and LBA Size Ranges Measured Aboard R/V Hakuho

\begin{tabular}{|c|c|c|c|c|}
\hline & \multicolumn{4}{|c|}{ Aerosol Size Range } \\
\hline & \multicolumn{2}{|c|}{$\mathrm{HBA}^{\mathrm{a}}$} & \multicolumn{2}{|c|}{$\mathrm{LBA}^{\mathrm{b}}$} \\
\hline & sub- $\mu$ & super- $\mu$ & sub- $\mu$ & super- $\mu$ \\
\hline $\mathrm{MSA}^{\mathrm{c}}$ & $99 \pm 14$ & $140 \pm 49$ & $38 \pm 5$ & $35 \pm 7$ \\
\hline Azelaic $\operatorname{acid}^{\mathrm{c}}\left(\mathrm{C}_{9}\right)$ & $0.53 \pm 0.19$ & $0.77 \pm 0.15$ & $0.24 \pm 0.07$ & $0.09 \pm 0.03$ \\
\hline $\left.\mathrm{ON}(\mathrm{ngN} \mathrm{m})^{-3}\right)$ & $273 \pm 48$ & $523 \pm 34$ & $133 \pm 16$ & $288 \pm 12$ \\
\hline $\left.\mathrm{OC}(\mathrm{ngC} \mathrm{m})^{-3}\right)$ & $630 \pm 104$ & $989 \pm 116$ & $394 \pm 42$ & $553 \pm 38$ \\
\hline $\mathrm{ON} / \mathrm{OC}$ & $0.43 \pm 0.23$ & $0.53 \pm 0.31$ & $0.34 \pm 0.07$ & $0.45 \pm 0.10$ \\
\hline $\mathrm{ON} / \mathrm{TN}$ & $0.73 \pm 0.22$ & $0.84 \pm 0.22$ & $0.67 \pm 0.18$ & $0.80 \pm 0.18$ \\
\hline $\mathrm{NO}_{3}^{-\mathrm{c}}$ & $16 \pm 15$ & $58 \pm 47$ & $32 \pm 25$ & $107 \pm 70$ \\
\hline $\mathrm{NH}_{4}^{+\mathrm{c}}$ & $48 \pm 7$ & $15 \pm 14$ & $96 \pm 37$ & $8 \pm 7$ \\
\hline Diethylammonium $^{\mathrm{a}}\left(\mathrm{DEA}^{+}\right)$ & $9 \pm 1$ & N.D. ${ }^{\mathrm{d}}$ & $1 \pm 1$ & N.D. ${ }^{\mathrm{d}}$ \\
\hline $\mathrm{nss}-\mathrm{SO}_{4}^{2-\mathrm{c}}$ & $553 \pm 325$ & $122 \pm 220$ & $578 \pm 229$ & $150 \pm 120$ \\
\hline $\mathrm{Na}^{+\mathrm{c}}$ & $335 \pm 200$ & $697 \pm 185$ & $229 \pm 79$ & $636 \pm 362$ \\
\hline $\mathrm{EC}\left(\mathrm{ngC} \mathrm{m}{ }^{-3}\right)$ & $21 \pm 6$ & $7 \pm 5$ & $43 \pm 8$ & $11 \pm 9$ \\
\hline$\delta^{15} \mathrm{~N}^{\mathrm{e}}(\%)$ & $3.2 \pm 0.9$ & $3.0 \pm 0.3$ & $7.2 \pm 0.7$ & $8.8 \pm 0.6$ \\
\hline$\delta^{13} \mathrm{C}^{\mathrm{e}}(\%)$ & $-23.7 \pm 0.8$ & $-23.4 \pm 0.7$ & $-25.1 \pm 0.2$ & $-25.6 \pm 1.1$ \\
\hline
\end{tabular}

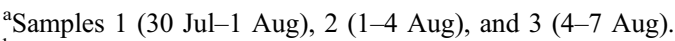

${ }^{\mathrm{b}}$ Samples 5 (9-12 Aug), 6 (12-15 Aug), 7 (15-17 Aug), and 8 (17-19 Aug).

${ }^{\mathrm{c}}$ Units are $\mathrm{ng} \mathrm{m}^{-3}$.

${ }^{\mathrm{d}}$ N.D. indicates that the concentration was not detectable.

${ }^{\mathrm{e}}$ Values are weight-averaged for each size fraction. 
results show that $\mathrm{ON}$ was a major component of aerosol TN in our study region.

[16] The ON peak detected in the submicrometer range (Figure 3a) suggests that $\mathrm{ON}$ undergoes gas-to-particle conversion as for $\mathrm{NH}_{4}^{+}$and nss- $\mathrm{SO}_{4}^{2-}$ (Table 1) [Cornell et $a l ., 2001]$ or that submicrometer aerosols contain oceanproduced $\mathrm{ON}$. Although it is difficult to prove the exact formation mechanism from our data alone, in situ production of $\mathrm{ON}$ by photochemical or biological processes in the aqueous phase of aerosol are also possible. The submicrometer concentrations of $\mathrm{DEA}^{+}$determined in this study are similar to those previously reported for the eastern North Atlantic by Facchini et al. [2008], who suggested that $\mathrm{DEA}^{+}$is derived from an oceanic biological source and is produced by the reaction of gaseous amines with sulfuric acid or acidic sulfates. On the other hand, $\mathrm{DEA}^{+}$was not detectable in the supermicrometer range (Table 1). ON was positively correlated with MSA in the submicrometer range of $\operatorname{HBA}\left(r^{2}=0.65\right.$, significant at $99 \%$ with 9 samples $)$, but not in the supermicrometer range. Because the production of MSA from DMS is also strongly linked to photochemical activity, this result points the similar processes of secondary production for the major fraction of $\mathrm{ON}$ in the submicrometer range.

[17] In the supermicrometer ranges of both HBA and LBA, $\mathrm{Na}^{+}$was dominant species. However, primary emission of $\mathrm{ON}$ with sea salts in supermicrometer particles may be less significant, because the peak diameter of ON (4.3$6.4 \mu \mathrm{m})$ is smaller than that of $\mathrm{Na}^{+}(6.4-10 \mu \mathrm{m})$. In addition, ON showed a positive correlation with MSA but not with $\mathrm{Na}^{+}$(data not shown). Although we did not determine water-soluble fraction of $\mathrm{ON}$, the presence of $\mathrm{ON}$ in the supermicrometer range implies that a major part of $\mathrm{ON}$ is of secondary origin. Possible formation pathways include condensation of gas-phase $\mathrm{ON}$ onto pre-existing sea salt particles in the supermicrometer range, coagulation of submicrometer particles with supermicrometer particles, and photochemical formation within clouds/fogs. Uptake of gaseous $\mathrm{ON}$ by dust particles seems unlikely, because $\mathrm{Ca}^{2+}$ concentrations in both size ranges were notably low in this study. Although we only identified $\mathrm{DEA}^{+}$as $\mathrm{ON}$ species, ON may consist of other biologically labile components, such as amino acids, urea [e.g., Simoneit et al., 2004], and more refractory components (e.g., humic compounds) [Cornell et al., 2003].

[18] To better understand the marine and terrestrial source contributions to $\mathrm{TN}$ and $\mathrm{TC}$, we analyzed nitrogen and stable carbon isotopic ratios for HBA and LBA as a function of particle size (Figures $3 \mathrm{c}$ and $3 \mathrm{~d}$ ). $\delta^{15} \mathrm{~N}$ values of TN in HBA ranged from $1.2 \%$ to $4.6 \%$, and those in LBA ranged from $5.2 \%$ to $9.9 \%$. We found that the weight-averaged $\delta^{15} \mathrm{~N}$ values $(3.1 \pm 0.2 \%$ o $)$ of HBA were substantially lower than those $(8.3 \pm 0.7 \%$ o $)$ of LBA. These $\delta^{15} \mathrm{~N}$ values overlap with a wide range of marine phytoplankton $(+3$ to $+12 \%)$ [Owens, 1988], whereas the values of LBA also overlap with values of $\mathrm{NO}_{\mathrm{x}}$ emitted from coal-fired boilers ( +6 to $+13 \%$ ) [Heaton, 1990]. It should be noted that nitrogen isotopic analysis alone cannot provide conclusive evidence about atmospheric ON sources [Kelly et al., 2005]. However, a clear difference in $\delta^{15} \mathrm{~N}$ values between HBA and LBA is consistent with the difference in mass concentrations of nitrogen species, suggesting that the sources and formation process of HBA and LBA are different.
[19] The higher $\delta^{15} \mathrm{~N}$ values of LBA, together with the higher concentrations of $\mathrm{NO}_{3}^{-}$(Table 1) particularly in the supermicrometer range, imply that at least some LBA nitrogen is of anthropogenic origin. Larger anthropogenic contribution to LBA is supported by the higher concentrations of EC and the back trajectories, suggesting that LBA are partly transported from continental sources (Figure 1b). Previous studies have indicated that the anthropogenic sources may significantly contribute to ON aerosols [e.g., Cornell et al., 2003]. However, due to the frequent fog occurrence in the studied area [Wang, 1985], scavenging of a large amount of anthropogenic nitrogen in gas and particles may result in the lower concentrations of ON in LBA.

[20] Stable carbon isotopic analysis can provide information on the distinction between marine and terrestrial aerosol sources. In HBA, $\delta^{13} \mathrm{C}$ values of TC ranged from $-26.1 \%$ o to $-22.0 \%$ (weight av. $-23.6 \pm 0.8 \%$ ), and those in LBA ranged from $-27.9 \%$ to $-24.2 \%$ (weight av. $-25.5 \pm$ $0.5 \%$ ). All the HBA size fractions were enriched with ${ }^{13} \mathrm{C}$ compared to those of LBA. In light of the minor $(<5 \%)$ contribution of EC to $\mathrm{TC}$, the difference in $\delta^{13} \mathrm{C}$ between HBA and LBA also supports the presence of biologicallyderived oceanic $\mathrm{ON}$ and $\mathrm{OC}$. To apportion the source of bulk OC, we assumed that most organic aerosol components in each size fraction were either (1) directly emitted and entrapped in the preexisting particles such as sea salt, or (2) produced to result in low volatility compounds that are partitioned primarily in the condensed phase rather than gaseous phase.

[21] In low- and mid-latitudes, $\delta^{13} \mathrm{C}$ of $\mathrm{OC}$ in sea water ranges from $-20 \%$ to $-22 \%$ [Turekian et al., 2003], whereas the average $\delta^{13} \mathrm{C}$ of terrestrial OC sources, such as fossil fuel combustion and biomass burning, is $-26.5 \pm 1 \%$ [e.g., Cachier et al., 1986]. To roughly calculate the relative contribution from marine and terrestrial OC sources, we applied $\delta^{13} \mathrm{C}$ values ranging from $-22 \%$ to $-21 \%$ for marine $\mathrm{OC}$ and those ranging from $-27 \%$ to $-26 \%$ for terrestrial OC following the equations given in previous studies [e.g., Turekian et al., 2003]. Our calculation indicates that marine sources contribute $\sim 46-72 \%$ for HBA and $\sim 8-36 \%$ for LBA. The average fractions in HBA are higher than those reported in marine air at Bermuda (av. 39\%) [Turekian et al., 2003] and in the high Arctic at Alert (av. 45\%) [Narukawa et al., 2008]. Our result suggests that marine biogenic ON and OC are important over the remote western North Pacific, where marine aerosols are less affected by a long-range atmospheric transport of anthropogenic aerosols and their precursors.

\section{Conclusions}

[22] We found a bimodal size distribution of ON and OC in marine aerosols over the western North Pacific in summer 2008. The average $\mathrm{ON}$ and $\mathrm{OC}$ concentrations are about twice more abundant in more marine biologically influenced aerosols than in less biologically influenced aerosols. These results together with back trajectory analysis provide an evidence of marine biological sources for both ON and OC.

[23] The average ON/OC ratio in more biologically influenced aerosols reached $0.49 \pm 0.11$, which was higher than that of less biologically influenced aerosols (0.35 \pm $0.10)$. Stable carbon isotopic analysis indicated that, on average, marine-derived carbon accounted for $\sim 46-72 \%$ of 
total carbon in more biologically influenced aerosols. These results indicate that organic aerosol over this region is enriched in $\mathrm{ON}$, the mass concentration of which is comparable to marine biogenic OC. We propose that aerosol ON is mainly produced by biological activity of the ocean where marine aerosols are less affected by anthropogenic nitrogen and emitted to the atmosphere via sea-surface microlayer.

[24] Acknowledgments. We acknowledge M. Uematsu for his organizing the R/V Hakuho cruise KH08-2. This research was supported by a Grant-in-Aid for Scientific Research from the Ministry of Education, Culture, Sports, Science and Technology, Japan.

\section{References}

Ayers, G. P., and J. L. Gras (1991), Seasonal relationship between cloud condensation nuclei and aerosol methanesulphonate in marine air, Nature, 353, 834-835, doi:10.1038/353834a0.

Cachier, H., M. P. Buat-Ménard, M. Fontugne, and R. Chesselet (1986), Long-range transport of continentally-derived particulate carbon in the marine atmosphere: Evidence from stable carbon isotope studies, Tellus, Ser. B, 38, 161-177.

Cooke, W. F., S. G. Jennings, and T. G. Spain (1997), Black carbon measurements at Mace Head, 1989-1996, J. Geophys. Res., 102, 25,33925,346, doi:10.1029/97JD01430.

Cornell, S., et al. (2001), Organic nitrogen in Hawaiian rain and aerosol, J. Geophys. Res., 106, 7973-7983, doi:10.1029/2000JD900655.

Cornell, S. E., et al. (2003), Organic nitrogen deposition on land and coastal environments: A review of methods and data, Atmos. Environ., 37, 2173-2191, doi:10.1016/S1352-2310(03)00133-X.

Duce, R. A., et al. (2008), Impacts of atmospheric anthropogenic nitrogen on the open ocean, Science, 320, 893-897, doi:10.1126/science.1150369.

Facchini, M. C., et al. (2008), Important source of marine secondary organic aerosol from biogenic amines, Environ. Sci. Technol., 42, 9116-9121, doi:10.1021/es8018385.

Hansell, D. A., and C. A. Carlson (2002), Biogeochemistry of Marine Dissolved Organic Matter, 774 pp., Academic, New York.

Heaton, T. H. E. (1990), ${ }^{15} \mathrm{~N} /{ }^{14} \mathrm{~N}$ ratios of $\mathrm{NO}_{\mathrm{x}}$ from vehicle engines and coal-fired power stations, Tellus, Ser. B, 42, 304-307, doi:10.1034/ j.1600-0889.1990.t01-1-00009.x.

Kawamura, K., and R. B. Gagosian (1987), Implications of $\omega$-oxocarboxylic acids in the remote marine atmosphere for photo-oxidation of unsaturated fatty acids, Nature, 325, 330-332, doi:10.1038/325330a0.
Kawamura, K., and K. Ikushima (1993), Seasonal changes in the distribution of dicarboxylic acids in the urban atmosphere, Environ. Sci. Technol., 27, 2227-2235, doi:10.1021/es00047a033.

Kawamura, K., and F. Sakaguchi (1999), Molecular distributions of water-soluble dicarboxylic acids in marine aerosols over the Pacific Ocean including tropics, J. Geophys. Res., 104, 3501-3509, doi:10.1029/1998JD100041.

Kawamura, K., et al. (2004), Organic and inorganic compositions of marine aerosols from East Asia: Seasonal variations of water soluble dicarboxylic acids, major ions, total carbon and nitrogen, and stable $\mathrm{C}$ and $\mathrm{N}$ isotopic composition, in Geochemical Investigations in Earth and Space Science: A Tribute to Isaac R. Kaplan, edited by R. J. Hill et al., Spec. Publ. Geochem. Soc., 9, 243-265.

Kelly, S. D., C. Stein, and T. D. Jickells (2005), Carbon and nitrogen isotopic analysis of atmospheric organic matter, Atmos. Environ., 39, 6007-6011, doi:10.1016/j.atmosenv.2005.05.030.

Narukawa, M., K. Kawamura, S.-M. Li, and J. W. Bottenheim (2008), Stable carbon isotopic ratios and ionic composition of the high-Arctic aerosols: An increase in $\delta^{13} \mathrm{C}$ values from winter to spring, J. Geophys. Res., 113, D02312, doi:10.1029/2007JD008755.

O'Dowd, C. D., et al. (2004), Biogenically driven organic contribution to marine aerosol, Nature, 431, 676-680, doi:10.1038/nature02959.

Owens, N. J. P. (1988), Natural variations in ${ }^{15} \mathrm{~N}$ in the marine environment, Adv. Mar. Biol., 24, 389-451, doi:10.1016/S0065-2881(08) 60077-2.

Savoie, D. L., et al. (2002), Marine biogenic and anthropogenic contributions to non-sea-salt sulfate in the marine boundary layer over the North Atlantic Ocean, J. Geophys. Res., 107(D18), 4356, doi:10.1029/ 2001JD000970.

Simoneit, B. R. T., M. Kobayashi, M. Mochida, K. Kawamura, and B. J. Huebert (2004), Aerosol particles collected on aircraft flights over the northwestern Pacific region during the ACE-Asia campaign: Composition and major sources of the organic compounds, J. Geophys. Res., 109, D19S09, doi:10.1029/2004JD004565.

Turekian, V. C., S. A. Macko, and W. C. Keene (2003), Concentrations, isotopic compositions, and sources of size-resolved, particulate organic carbon and oxalate in near-surface marine air at Bermuda during spring, J. Geophys. Res., 108(D5), 4157, doi:10.1029/2002JD002053.

Wang, B.-H. (1985), Distributions and variations of sea fog in the world, in Sea Fog, pp. 51-90, China Ocean, Beijing.

Zhang, Q., C. Anastasio, and M. Jimenez-Cruz (2002), Water-soluble organic nitrogen in atmospheric fine particles $\left(\mathrm{PM}_{2.5}\right)$ from northern California, J. Geophys. Res., 107(D11), 4112, doi:10.1029/ 2001JD000870.

K. Kawamura, Y. Miyazaki, and M. Sawano, Institute of Low Temperature Science, Hokkaido University, Kita-19, Nishi-8, Kita-ku, Sapporo, Hokkaido 060-0819, Japan. (yuzom@pop.lowtem.hokudai.ac.jp) 